\title{
Evaluation of Level of Service of Traffic at Major Road Intersections in Ibadan, Nigeria
}

\author{
* Osuolale, O. M., Durodola, T. A. and Soladoye, E. O. \\ Department of Civil Engineering, Faculty of Engineering and Technology, \\ Ladoke Akintola University of Technology, PMB 4000, Ogbomoso. Nigeria. \\ E-mail: *omosuolale@lautech.edu.ng
}

\begin{abstract}
Transportation has been of immense benefits to the social, economic and political development of communities, however, it is sometimes characterised with negative impacts such as traffic congestions, delays, environmental pollutions and crashes. In this study, the level of service of selected major road intersections in Ibadan were investigated. Traffic volume of each intersection approach was conducted from $7 \mathrm{am}-7 \mathrm{pm}$ on Mondays, Wednesdays and Saturdays, delay studies were carried out during the morning, afternoon and evening peak hours and level of service for each approach was determined from the average delay per vehicle. The traffic volume reveals that passenger cars are the predominant vehicles at all the approaches and the morning and afternoon peak hours occurred between 8 to $9 \mathrm{am}$ and 2 to $3 \mathrm{pm}$, respectively. The level of service for all the approaches is B, indicating slight reduction in capacity of the intersections.
\end{abstract}

Keywords: Transport, Traffic volume, Traffic delay, Traffic congestion and Road intersection

DOI: $10.7176 /$ JIEA/9-7-05

Publication date: December $31^{\text {st }} 2019$

\section{Introduction}

The provision of transportation facilities for the movement of persons, goods and services is very germane for the socioeconomic development of any community (Dukiya and Ajiboye, 2011). The various modes of transportation facilities that are in-use in Nigeria are highways, railways, waterways, pipelines and conveyors but the widely used mode is the highway (Kadiyali, 1999). Most cities in Nigeria are characterised with economic activities that require movement of persons, goods and services. Therefore, efficient planning, functional design, operation, control and management of transportation networks should be a great concern of government at all levels if major cities in Nigeria, the populace and corporate business owners will enjoy economic and social prosperity.

Good transportation facilities are characterize with so many positives such as the one described above but not without some negatives, such as: traffic delay and congestion, road traffic accidents, environmental pollution and so on. The challenge of traffic congestions are at alarming rate in many of Nigeria's major urban centres, they are becoming a great threat to free flow of traffic in these cities. These problems stem from the inefficient use of road space and increase in the number of vehicles on our roads due to crave for personal mobility (Atomode, 2013). Traffic congestion had been defined by various researchers based on their perspectives, Salter, 1984 illustrated traffic congestion at road intersection in terms of a vehicle transferring from its route to another route, crossing any other traffic streams which flow between it and its destinations. These manoeuvres are always complex at intersections due to the fact that other vehicles attempting to cross or merge with other streams are likely to experience delays and all these may result in traffic congestion.

OECD and ECMT (2007) at the joint transport research centre came up with following definitions of traffic congestion to reflect the various broad perspectives:

- Congestion is a condition where demand for road space is more than supply.

- Congestion is the impedance vehicles impose on one another base on the fundamental principle of traffic flow (speed-flow), in conditions where the use of a transport system approaches capacity.

- Congestion is basically an event linked to the difference between the performance expectation of roadway system's users and the actual performance of the system.

A variety of researchers have studied traffic congestion from different perspective : Atomode (2013) investigated traffic delay and possible causes at selected road intersections in Ilorin, Nigeria. The author used characteristics of the intersections, traffic volume and delay to evaluate the performance of the intersections. His findings revealed that there are variations traffic flows and delays at the intersections, the traffic volumes correlate with the delays, therefore, the higher the traffic volume, the higher the traffic congestion. He identified the performance of the 
traffic warden officers and parking as major causes of the traffic congestion. He did not evaluate the cost of the traffic delay and his findings are localised. Ukapata and Etika (2012) studied the causes of traffic congestion in major cities of Nigeria using questionnaire survey among transportation and non transportation professionals. The results revealed the following possible causes of traffic congestion: poor driving habits, poor road network, inadequate road capacity and lack of parking facilities. The study carried out by Oyedepo and Afolayan (2016) evaluated economic and productivity losses using average daily traffic, travel speed, fuel consumption and traffic delay along selected routes in Akure, Nigeria. The authors findings showed that the annual person hours of delays, daily wasted fuel cost for vehicles, total delay cost and fuel wasted associated with congestion for the three routes were (626.25, 918.51 and 140.91 hrs), (N785.83/day, N 959.9/day and N 130.5/day), (N6,506.42, N 7,676.63 and $\mathrm{N} 2$ 2,110.92) and $(1,642,352.40$ naira per year, $1,937,735.8$ naira per year, and 532,838.80 naira per year) respectively. It was concluded that the traffic congestion resulted in economic losses.

Laoye et. al., 2016 studied indices of traffic congestion on major roads in Akure, Nigeria. The authors collected traffic volume at selected sections of the roads and spot speed, density, delay and headway at intersections. The following parameters were determined from the analysis of the data: volume-capacity ratio, minimum allowable speed, jam density and critical delay revealed, the parameters were used as indices for evaluating traffic congestion. It was concluded that from the indices that some of the routes were moderately congested and the others were heavily congested. Dukiya and Ajiboye (2011) examined delay factors, time wastage and traffic conflicts at urban intersections in Lagos, Nigeria. The authors used delay analytical tool, vehicle spot speed and traffic volume to assess traffic congestion. It was revealed that the intersections had Level of Service (LOS) ranging from B, C, D and E. The worse LOS was obtained during the evening peak hour especially for traffic warden controlled intersections.

\section{Methodology}

Traffic field studies were conducted at two major road intersections in Ibadan based the volume of vehicles and perceived delay observed during reconnaissance survey. The studies were carried out between $19^{\text {th }}$ and $31^{\text {st }} \mathrm{July}$, 2010 and they include inventory, traffic volume, delay and conflict studies.

\subsection{Inventory survey}

The inventory survey of the study locations were conducted in order to determine the physical characteristics of the road intersections, type of vehicles using the intersections and type of traffic control. The descriptive information of two road intersections are presented in Table 1.

Table 1: Intersection characteristics and land-use pattern

\begin{tabular}{|l|l|l|l|l|}
\hline S/N & $\begin{array}{l}\text { Name of } \\
\text { Intersection }\end{array}$ & Geometric Features & Type of Traffic & Land-use Characteristics \\
\hline 1. & Mokola & $\begin{array}{l}\text { 4 -legged intersection with } \\
\text { raised median on all the } \\
\text { approaches }\end{array}$ & $\begin{array}{l}\text { Traffic is } \\
\text { heterogeneous } \\
\text { and heavy }\end{array}$ & $\begin{array}{l}\text { Mixed development comprises } \\
\text { commercial centres, Retail shops, } \\
\text { Commercial motor parks, Markets, } \\
\text { Residential areas }\end{array}$ \\
\hline 2. & Total Garden & $\begin{array}{l}4 \text {-legged intersection with } \\
\text { raised median on all the } \\
\text { approaches }\end{array}$ & $\begin{array}{l}\text { Traffic is } \\
\text { heterogeneous } \\
\text { and heavy }\end{array}$ & $\begin{array}{l}\text { Mixed development comprises } \\
\text { commercial centres, Institutional } \\
\text { areas, Retail shops, Markets, } \\
\text { Residential areas }\end{array}$ \\
\hline
\end{tabular}

\section{$2.2 \quad$ Traffic volume study}

Traffic volume studies were carried out at each approach of the two intersections from 7:00am to 7: 00pm on Mondays, Wednesdays and Saturdays to capture the traffic scenarios at the beginning of the week, mid-week and weekend respectively. The data collected were analysed to determine average daily traffic (ADT), peak hour volume (PHV) and non peak hour volume (NPV) for each approach.

\subsection{Traffic delay study}

The intersection traffic delay study were carried out using method described in Overseas road note 11 (TRL, 1993). The number of stopped vehicles queuing on each approach to the road intersections was counted at interval of fifteen seconds. It carried out during the peak and non peak hours. 


\section{Results and Discussion}

\subsection{Traffic volume based on classification}

The traffic volume at both Mokola and Total Garden road intersections based on vehicle classification are presented in Figure 1 and 2, respectively. The class of vehicle that is mostly used for transport is the passenger car and it accounted for $43.49 \%$ of the vehicles at Mokola intersection, others are motorcycles, buses and trucks with 29.94, 23.22 and $3.36 \%$, respectively. The trend was the same for morning, afternoon and evening peak and non peak hours, it is in agreement with the findings of Ajayi et al., 2016. The high percentage of passenger cars can be attributed to the land use pattern of the area, desire for personal mobility of the residents and major means of transit in Ibadan, which is the commercial taxis. The low percentage of trucks can be attributed to the nature of commercial activities around the area, the few trucks are the ones supplying fuels to the filling stations and goods to big shops within the area. The Total Garden intersection has a similar trend like the Mokola intersection, the percentage is $42.70,26.67,25.18$ and $5.45 \%$ for passenger cars, motorcycles, buses and trucks, respectively. The reason for this trend is similar to the ones deduced for Mokola intersection. However, The number of buses were slightly higher than the number of motorcycles during the morning hours of 7:00 am to 11: $00 \mathrm{am}$. This slight change could be due to weather (rainfall) condition during the traffic study.

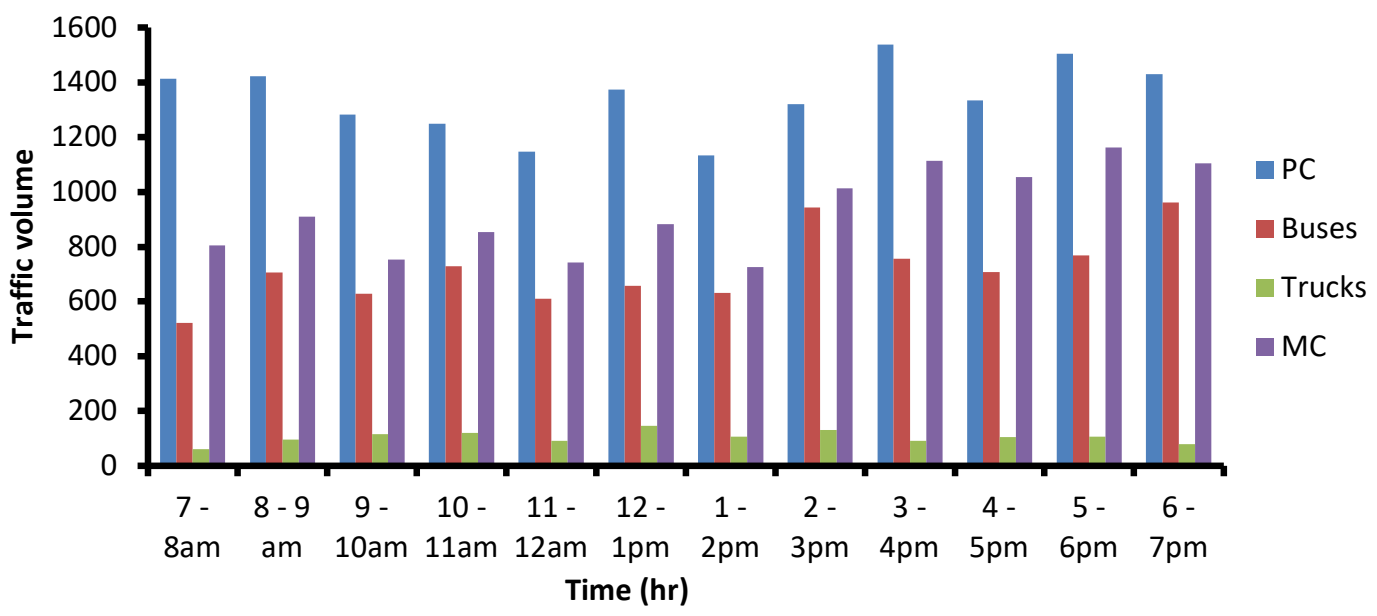

Figure 1: Average hourly daily traffic volume based on vehicle classification (Mokola Intersection)

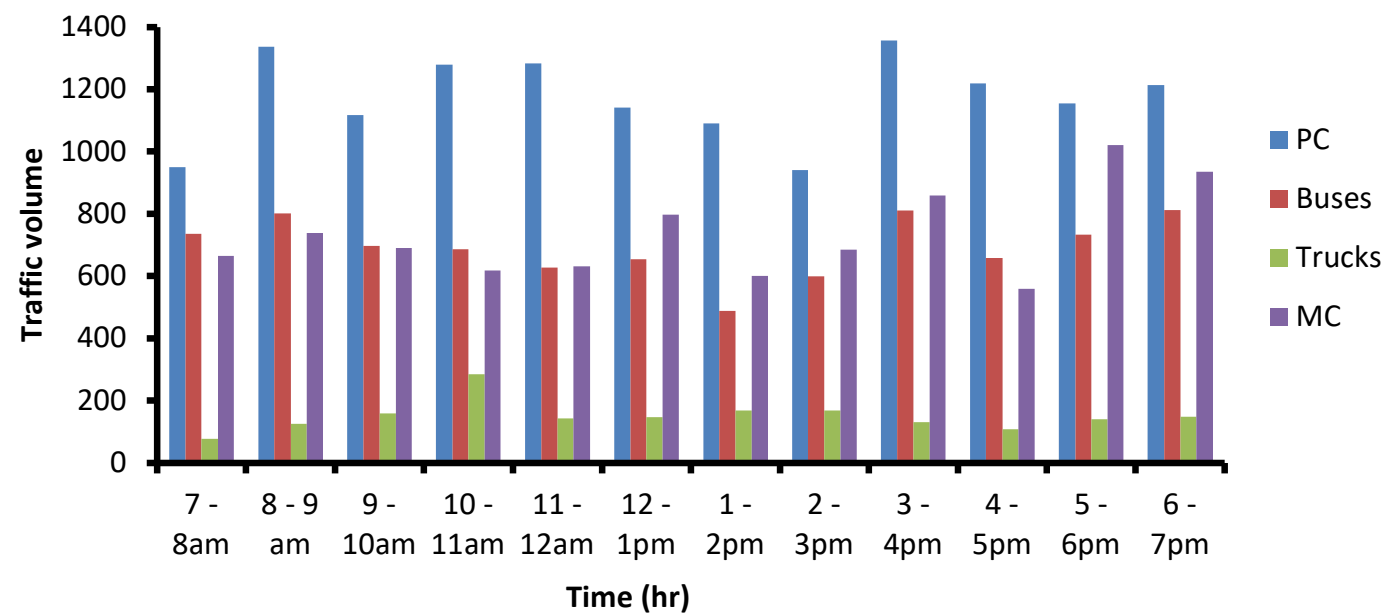

Figure 2: Average hourly daily traffic volume based on vehicle classification (Total Garden Intersection)

\subsection{Traffic volume based on day of the week}

The traffic volume at both Mokola and Total Garden road intersections based on days of the week are presented in Figure 3 and 4, respectively. The highest traffic volume was observed on Mondays for all the hourly studies except 
at Mokola intersection with the highest on Saturdays from 10 am to $7 \mathrm{pm}$. This exception could be due to either road diversion or special occasion around the intersection. The second highest volume of traffic was on Wednesdays followed by Saturdays.

The morning peak hours for Mondays and Wednesdays occurred between 7 - 8 am and 8 - 9am. This is due early morning rush to works and schools by workers and students. The morning peak hour for Saturdays was between 10 and $11 \mathrm{am}$, this could be attributed to relaxation during the weekend by most workers and students. This is similar to the findings of Osuolale et al., 2007. The afternoon peak hours for Mondays, Wednesdays and Saturdays occurred between $2-3 \mathrm{pm}$ and $3-4 \mathrm{pm}$. It can be attributed to closing hour of schools, some offices and returning back home of shoppers. The evening peak hours for Mondays, Wednesdays and Saturdays are between 5-6pm and $6-7 \mathrm{pm}$. This is due to workers and shop owners that are returning to their various residents. The peak hour periods can be used by traffic management agency for effective traffic control through various measures.

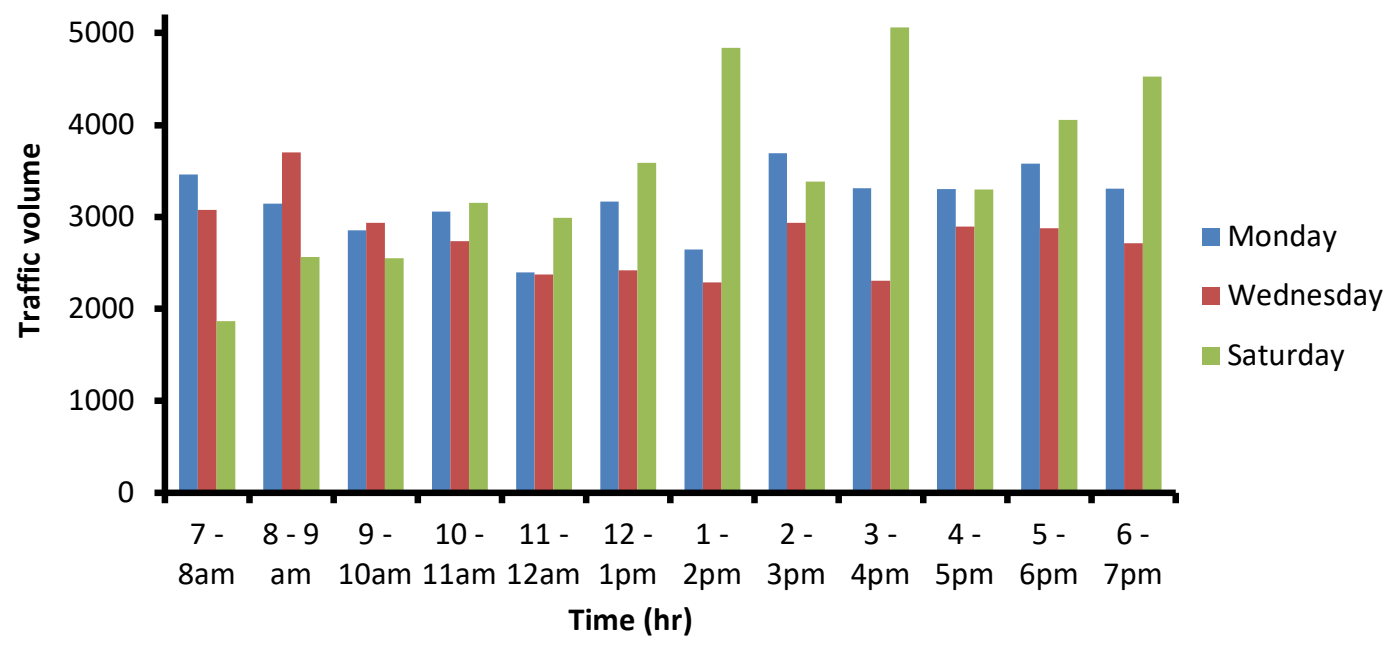

Figure 3: Average hourly daily traffic volume at Mokola Intersection

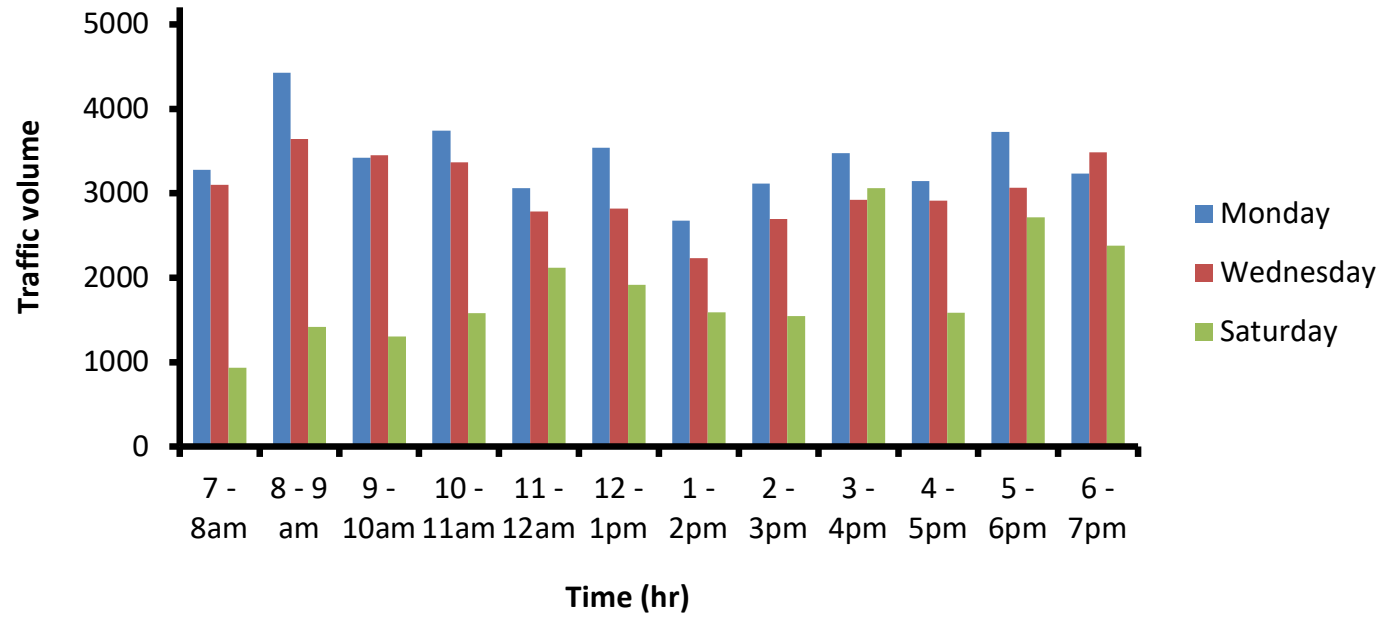

Figure 4: Average hourly daily traffic volume at Total Garden Intersection

\subsection{Delay and level of service at Intersections}

The average delay per vehicle and the level of service for each approach for the Mokola and Total Garden road intersections are presented in Table 2 and 3. The average delay per vehicle ranged from 11.3 to $12.9 \mathrm{~s}$ and 12.2 to $13.6 \mathrm{~s}$ for the Mokola and Total Garden intersections, respectively. From the average delay results, all the intersection approaches are on level of service B, which indicates that some vehicles arrived the intersection approaches before they were given passage at the intersections. Also, the number of vehicles at the intersection approaches is greater than that of LOS A, but progression is still good. The result of LOS during these studies is 
not in tandem with the earlier research of Osuolale et al., 2007 because the approach volume at Ibadan is less when compare with the research at Lagos. In practical sense, the LOS B shows the amount of lost travel time, fuel consumption and the measure of frustration and discomfort experience by the motorist at the intersections (Garber and Hoel, 2009)

Table 2: Average delay and Level of Service for Mokola Intersection

\begin{tabular}{|c|l|c|c|}
\hline Approach & \multicolumn{1}{|c|}{ Period } & $\begin{array}{c}\text { Average Delay per } \\
\text { Vehicle (s) }\end{array}$ & $\begin{array}{c}\text { Level of } \\
\text { Service }\end{array}$ \\
\hline \multirow{3}{*}{ Northbound } & Morning peak hour & 11.5 & $\mathrm{~B}$ \\
\cline { 2 - 4 } & Afternoon peak hour & 11.6 & $\mathrm{~B}$ \\
\cline { 2 - 4 } & Evening peak hour & 11.3 & $\mathrm{~B}$ \\
\hline \multirow{3}{*}{ Southbound } & Morning peak hour & 12.2 & $\mathrm{~B}$ \\
\cline { 2 - 4 } & Afternoon peak hour & 11.9 & $\mathrm{~B}$ \\
\cline { 2 - 4 } & Evening peak hour & 11.5 & $\mathrm{~B}$ \\
\hline \multirow{3}{*}{ Eastbound } & Morning peak hour & 11.5 & $\mathrm{~B}$ \\
\cline { 2 - 4 } & Afternoon peak hour & 11.5 & $\mathrm{~B}$ \\
\cline { 2 - 4 } & Evening peak hour & 12.1 & $\mathrm{~B}$ \\
\hline & Morning peak hour & 12.9 & $\mathrm{~B}$ \\
\cline { 2 - 4 } & Afternoon peak hour & 12.7 & \\
\cline { 2 - 4 } & Evening peak hour & 12.4 & \\
\hline
\end{tabular}

Table 3: Average delay and Level of Service for Total Garden Intersection

\begin{tabular}{|c|l|c|c|}
\hline \multirow{2}{*}{ Approach } & \multicolumn{1}{|c|}{ Period } & $\begin{array}{c}\text { Average Delay per } \\
\text { Vehicle (s) }\end{array}$ & $\begin{array}{c}\text { Level of } \\
\text { Service }\end{array}$ \\
\hline \multirow{3}{*}{ Northbound } & Morning peak hour & 12.7 & $\mathrm{~B}$ \\
\cline { 2 - 4 } & Afternoon peak hour & 13.1 & $\mathrm{~B}$ \\
\cline { 2 - 4 } & Evening peak hour & 13.3 & $\mathrm{~B}$ \\
\hline \multirow{3}{*}{ Southbound } & Morning peak hour & 12.6 & $\mathrm{~B}$ \\
\cline { 2 - 4 } & Afternoon peak hour & 13.2 & $\mathrm{~B}$ \\
\cline { 2 - 4 } & Evening peak hour & 13.3 & $\mathrm{~B}$ \\
\hline \multirow{3}{*}{ Westbound } & Morning peak hour & 12.8 & $\mathrm{~B}$ \\
\cline { 2 - 4 } & Afternoon peak hour & 13.0 & $\mathrm{~B}$ \\
\cline { 2 - 4 } & Evening peak hour & 12.8 & $\mathrm{~B}$ \\
\hline \multirow{3}{*}{ Eastbound } & Morning peak hour & 12.2 & $\mathrm{~B}$ \\
\cline { 2 - 4 } & Afternoon peak hour & 13.1 & $\mathrm{~B}$ \\
\cline { 2 - 4 } & Evening peak hour & 13.6 & \\
\hline
\end{tabular}

\section{Conclusion}

The composition of traffic using the intersections are passenger cars, motorcycles, buses and trucks but greater than $40 \%$ are passenger cars. The traffic volume studies revealed that morning peak hour is from 8 to 9 am and the afternoon is from 2 to $3 \mathrm{pm}$. The level of service for all the approaches is B. The performance at the intersection shows that some vehicles arrived before given the right of way, therefore, there is slight congestion with some interruption of manoeuvrability.

\section{References}

Atomode, T. I. (2013). Assessment of traffic delay problems and characteristics at urban road intersections: A case study of Ilorin, Nigeria. IOSR Journal of Humanities and Social Science, 12(4): 6-16.

Arosanyin, G. T. (1998). Determination of transport output in Nigeria. Journal of Transport Studies, 2(1): 69-78.

Badejo, D. (1999). Maritime transport in Nigeria economy. Rex Charles Publishers, Ibadan.

Dukiya, J. J. and Ajiboye, A. O. (2011). Performance analysis of urban road intersection and its environmental implication: A case study of the Lagos metropolitan area. Urban Transport XVII, 116: 167-178.

Garber, N. J. and Hoel, L. A. (2009). Traffic and highway engineering, fourth edition, Cengage Learning, Toronto, Canada.

Kadiyali, L. R. (1999). Traffic engineering and transport planning, Khana Publisher, India. 
Laoye, A. A. Owolabi, A. O. and Ajayi, S. A. (2016). Indices of traffic congestion on major roads in Akure, a developing city in Nigeria. International Journal of Scientific and Engineering Research, 7(6): 434-443.

OECD (Organization for Economic Cooperation and Development) and ECMT (European Conference of Ministers of Transport) (2007). Managing urban traffic congestion, Joint Research Centre, ECMT Publishing, France.

Ogunsanya, A. A. (2004). Analysis of Nigerian government policy on urban transportation, Nigerian Institute of Transport Technology, Zaria, 2003 - 223.

Osuolale, O. M., Okewusi, R. E. and Adewuyi, A. P. (2007). A comparative evaluation of manual and automatic methods of traffic control at some road intersections in Lasos, Nigeria, Journal of Research Information in Civil Engineering, 4(1): 1 -16.

Oyedepo, J. O. and Afolayan, A (2016). Evaluating vehicular delay cost of congestion road networks in Akure, Ondo State, Nigeria. Journal of Applied Science and Process Engineering, 3(2): 90 - 99. 